
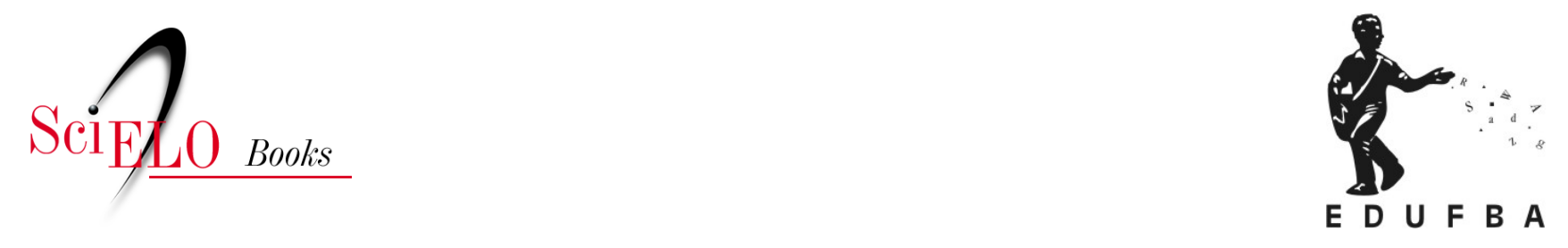

\title{
Avaliação nutricional \\ conceitos e importância para a formação do nutricionista
}

\author{
Maria da Conceição Monteiro da Silva \\ Lílian Ramos Sampaio
}

\section{SciELO Books / SciELO Livros / SciELO Libros}

SILVA, M.C.M., and SAMPAIO, L.R. Avaliação nutricional: conceitos e importância para a formação do nutricionista. In: SAMPAIO, L.R., org. Avaliação nutricional [online]. Salvador: EDUFBA, 2012, pp. 15-21. Sala de aula collection. ISBN: 978-85-232-1874-4.

https://doi.org/10.7476/9788523218744.0003.

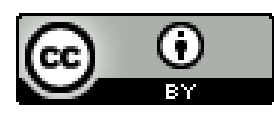

All the contents of this work, except where otherwise noted, is licensed under a Creative Commons Attribution $\underline{4.0 \text { International license. }}$

Todo o conteúdo deste trabalho, exceto quando houver ressalva, é publicado sob a licença Creative Commons Atribição 4.0.

Todo el contenido de esta obra, excepto donde se indique lo contrario, está bajo licencia de la licencia Creative Commons Reconocimento 4.0. 


\section{Avaliação nutricional: conceitos e importância para a formação do nutricionista}

Maria da Conceição Monteiro da Silva Lílian Ramos Sampaio

Ao iniciar o estudo da avaliação nutricional, faz-se necessário apropriar-se de alguns conceitos, começando pelo significado de avaliação, de estado nutricional e, por fim, de avaliação do estado nutricional. Assim, avaliar, de acordo com o dicionário de Aurélio Buarque, significa: "julgar"; "fazer apreciação", ou seja, comparar resultados com referências, parâmetros e valores cientificamente, tecnicamente ou politicamente aceitos.

Para o conceito de "estado nutricional", adotamos o proposto por Vasconcelos (2008), por incorporar a dimensão biológica (manifestação biológica sobre o corpo da relação entre consumo e as necessidades nutricionais) e social (manifestação biológica das relações que se operam sobre o corpo no interior 
da sociedade). Dessa forma, o autor conceitua estado nutricional como a síntese orgânica das relações entre o homem, a natureza e o alimento, as quais se estabelecem no interior de uma sociedade. Portanto, para a avaliação do estado nutricional de um individuo ou grupo populacional, é necessária a utilização de métodos de coleta e procedimentos diagnósticos que possibilitem determinar o estado nutricional, assim como as causas prováveis que deram origem ao(s) problema(s) nutricional(is), para que medidas de intervenção sejam planejadas, executadas e monitoradas nos âmbitos individual ou coletivo.

Em referência aos conceitos apresentados, a avaliação do estado nutricional tem como objetivo identificar distúrbios e riscos nutricionais, e também a gravidade desses, para então traçar condutas que possibilitem a recuperação ou manutenção adequada do estado de saúde. O monitoramento do paciente, através da avaliação nutricional, também é muito importante para acompanhar as respostas do indivíduo às intervenções nutricionais. Outros usos da avaliação nutricional de grande relevância: na vigilância alimentar e nutricional nos diferentes ciclos da vida; no diagnóstico da magnitude e distribuição geográfica dos problemas nutricionais; na tomada de decisão para intervenção nutricional no âmbito das políticas e dos programas públicos de combate aos problemas nutricionais mais relevantes considerados como sendo de saúde pública e no monitoramento dos efeitos da intervenção nutricional nos âmbitos individual e coletivo.

O conceito de estado nutricional aqui adotado implica na concepção de um modelo multicausal de determinação dos problemas nutricionais que aumenta sua complexidade na medida em que incorpora uma hierarquização no processo de causalidade. Este modelo parte de causas básicas/estruturais que expressam os processos econômicos, políticos e ideológicos da organização 
social, o desenvolvimento das forças produtivas e as relações de produção. Este, então, segue para um nível de determinação intermediário (mediato), que tem a ver com as relações de organização de produção e consumo de cada classe social, e, finalmente, atinge o nível de determinação mais imediato ou individual que se relaciona com a influência de fatores biológicos, ambientais, econômicos, sociais (quanto à saúde e à educação), culturais e ideológicos e com a forma como se organiza a produção e o consumo familiar e individual. Este último nível se relaciona mais diretamente com a dimensão biológica quando considera a relação entre ingestão alimentar e gasto energético. Assim, em ultima instância, é no desequilíbrio entre o consumo alimentar e o gasto energético que se observam as alterações no estado nutricional ao nível do corpo biológico.

O desequilíbrio entre consumo e necessidades nutricionais, em decorrência do consumo insuficiente para atender as necessidades nutricionais, pode ter como consequência doenças carenciais, a exemplo da desnutrição energético protéica, anemia ferropriva, hipovitaminose A, bócio, cárie dental, dentre outras carências nutricionais. No caso do excesso de consumo, tem-se a obesidade, excesso de algumas vitaminas e minerais, as dislipidemias e algumas doenças crônicas não transmissíveis, como a hipertensão, o diabetes não insulino dependente e alguns tipos de câncer. Pelo exposto, a definição dos métodos a serem utilizados na avaliação do estado nutricional tem relação com a identificação das manifestações orgânicas dos problemas nutricionais ao nível do corpo, denominados de métodos diretos, e com a identificação das causas desses problemas, denominados de indiretos. Os métodos diretos são classificados, ainda de acordo com o tipo de abordagem, em objetivos (abordagem quantitativa) e subjetivos (abordagem qualitativa). Os métodos objetivos compreen- 
dem os exames antropométricos (peso, altura, dobra cutânea etc); exames laboratoriais (hemoglobina, colesterol etc); exame clínico nutricional (sinais e sintomas clínicos nutricionais) e métodos sofisticados como a densitometria, bioimpedância etc. Quanto aos subjetivos, tem-se a semiologia nutricional, a avaliação subjetiva global e a avaliação muscular subjetiva.

Os métodos indiretos buscam identificar os fatores associados ao processo de determinação do estado nutricional, ou seja, aqueles que explicam a ocorrência do problema nutricional, além de identificarem indivíduos ou grupos em risco nutricional. São os demográficos (sexo, idade, faixa etária, morbidade, mortalidade etc); socioeconômicos (salário, ocupação, escolaridade, acesso ao serviço de saúde etc.); culturais (tabus alimentares, características locais específicas); estilo de vida (atividade física, hábito de fumar e consumir bebida alcoólica, etc.) e de inquérito de consumo alimentar (recordatório alimentar de 24 horas, frequência alimentar, pesada direta etc.). A associação de todos esses métodos é imprescindível para melhorar a acurácia e precisão do diagnóstico.

Com o apoio dos métodos diretos e indiretos podem ser construídos os indicadores do estado nutricional. A partir dessa premissa e de posse do conhecimento epidemiológico e clinico do processo de determinação dos problemas nutricionais, é possível direcionar e ampliar as informações a serem obtidas, considerando a queixa do paciente e fatores ambientais, com sua influência no acesso ao alimento, genéticos (hereditariedade, predisposição ao desenvolvimento de doenças etc) e psicológicos (anorexia, bulimia, ansiedade, etc). Dessa forma, durante o atendimento nutricional, o nutricionista deve estar atento a todas essas condições, no sentido de potencializar a eficácia da intervenção nutricional. Considerando a variabilidade dos métodos para avaliação do estado nutricional, é necessário saber escolhê-los. Para a escolha 
dos métodos adequados para aplicação em determinada situação é importante a apropriação de alguns conhecimentos, tais como: distinguir uma avaliação para coletividade (pesquisa) de uma avaliação nutricional individual, pois, apesar do mesmo objetivo - correção e/ou manutenção do estado nutricional adequado -, existem métodos que são possíveis de se desenvolver em uma avaliação individual, mas que não se aplicam em populações/ coletividades; a epidemiologia do problema a ser investigado e as formas de manifestações orgânicas dos problemas nutricionais, assim como o conhecimento sobre a validade dos métodos em termos de sensibilidade e especificidade para o diagnóstico do problema nutricional a ser investigado. Ou seja, a escolha do método a ser utilizado dependerá inicialmente do objetivo da avaliação e dos problemas a serem investigados.

Agrega-se ainda à diversidade de elementos a serem avaliados e considerados para escolha do método adequado à faixa etária em questão as condições do espaço físico para o exame e a disponibilidade dos instrumentos, dentre outros quesitos. A avaliação nutricional pode ser individual ou coletiva, a depender do método utilizado: clínico ou epidemiológico.

A avaliação de populações ou coletividades apresenta caráter mais abrangente, uma vez que aborda a questão com maior ênfase na dimensão social, possibilitando o diagnóstico e a explicação dos fatores de determinação para um dado grupo ou população, que conduz a ações de promoção e prevenção para a coletividade, e não para o indivíduo.

A avaliação nutricional de coletividades, mais utilizada por profissionais que atuam na área da saúde coletiva, será abordada em um capítulo específico no segundo volume desta série didática. 
A avaliação nutricional do indivíduo, ou avaliação nutricional no âmbito da clínica, é uma ação desenvolvida pelo nutricionista no seu processo de trabalho domiciliar, ambulatorial e hospitalar. Para a realização da avaliação nutricional, há a necessidade do uso do raciocínio clínico e investigativo para associar o conhecimento técnico e cientifico à habilidade na utilização de métodos e técnicas de diagnóstico e ao processo de determinação dos problemas nutricionais.

\section{Considerações Finais}

Em quase todas as áreas de atuação, o nutricionista terá que fundamentar a sua prática em informações sobre o perfil nutricional do indivíduo ou grupos populacionais. Assim, avaliar o estado nutricional de um indivíduo ou de uma coletividade é um instrumental importante no processo de trabalho do nutricionista nas diferentes áreas de atuação, a saber: i) $\mathrm{Na}$ área da alimentação coletiva, necessária para o planejamento dos cardápios, de acordo com as condições de saúde e nutrição da clientela; para o monitoramento do estado nutricional e para ações educativas ou outras intervenções necessárias para promoção da saúde, alimentação saudável e prevenção de problemas nutricionais; ii) No que se refere à nutrição e saúde pública, conhecer o estado nutricional da população é de fundamental importância para o planejamento de políticas públicas e programas na área da alimentação e nutrição; para o monitoramento e execução de ações de promoção da alimentação saudável e de prevenção dos distúrbios nutricionais; iii) $\mathrm{Na}$ nutrição clínica, em que a obtenção do diagnóstico nutricional e as causas a ele relacionadas é condição necessária para 
a elaboração do plano de atenção alimentar e nutricional para o paciente, incluindo a prescrição da dieta.

Diante de uma nova sociedade detentora de um conhecimento ampliado referente à alimentação, ciente dos muitos malefícios e benefícios trazidos por certos alimentos, somados à realidade de transição nutricional e às mudanças nos padrões alimentares, o nutricionista deve estar bem preparado, atualizado e possuir segurança tanto na utilização como na interpretação dos diversos métodos de avaliação nutricional.

\section{Referências}

GIBSON, R. S. Anthropometric assessment of growth. In: Gibson R. S. Principles of nutritional assessment. New York: Oxford University Press, 1990. p. 163-186.

UNIVERSIDADE FEDERAL DA BAHIA. Escola de Nutrição Avaliação nutricional: componente curricular NUT 143. Salvador, 200-?.

VASCONCELOS, Francisco de Assis Guedes. Avaliação nutricional de coletividades. 4. ed. rev. e amp. Florianópolis: Ed. UFSC, 2008. 186 p. 